\title{
Stock Returns And Disagreement Among Sell-Side Analysts
}

Jeffrey Hobbs, Appalachian State University, USA

David L. Kaufman, The University of Michigan-Dearborn, USA

Hei-Wai Lee, The University of Michigan-Dearborn, USA

Vivek Singh, The University of Michigan-Dearborn, USA

\begin{abstract}
Asymmetric information, investor optimism, and unbiased prices hypotheses are the main hypotheses proposed for explaining how investors' difference of opinion may impact stock returns. We use a new measure for divergence in investor beliefs among sell-side analysts to test these three hypotheses. Our initial findings are not supportive of either the asymmetric information or the investor optimism hypotheses. However, since these two hypotheses predict opposing effects of divergence in opinion on stock returns, the effects could neutralize their respective impacts on stock prices. Our further empirical analysis though suggests that this is not the case. The weight of the evidence presented suggests that within the sell-side, the difference of opinion does not impose a bias on future stock returns.
\end{abstract}

Keywords: Asymmetric Information; Difference of Opinion; Investor Optimism; Unbiased Prices

\section{INTRODUCTION}

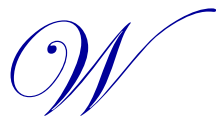
e examine three main hypotheses postulated for disentangling conflicting evidences regarding the effect of investor difference of opinion on stock prices. As per the asymmetric information hypothesis, the level of difference of opinion reflects the extent of asymmetric information about firm value. This suggests an initial discount in stock valuation, and hence lower initial return, followed by higher return that accompanies greater risk (Varian, 1985; Merton, 1987; Doukas, Kim, \& Pantzalis, 2006; Garfinkel and Sokobin, 2006). That is, the asymmetric information hypothesis predicts lower returns followed by higher returns for stocks that investors hold different opinions.

The investor optimism hypothesis (Miller, 1977), on the other hand, posits that when pessimistic investors face shortselling restrictions, divergence of investors' beliefs may result in "optimistic prices" that only reflect the optimistic investors' opinions. Thus, greater difference of opinion among investors or more shorting restrictions yield more upward bias in prices, and hence higher initial returns. Later, when there is a correction in the overvaluation of the stock, we expect negative abnormal returns. That is, the investor optimism hypothesis predicts higher returns followed by lower returns, which contradicts the prediction of the asymmetric information hypothesis.

It is possible that the competing effects of these two hypotheses could be working at the same time, resulting in a neutralization that yields unbiased stock returns. A third hypothesis is the unbiased prices hypothesis, which has been under recognized in the literature, predicts that despite rational investors' difference of opinion, stock prices remain unbiased with future abnormal returns close to zero on average. In their models that support this hypothesis, Diamond and Verrecchia (1987) assume that rational market makers, who have knowledge of all public information and with unlimited computational power, play a dominating role in stock valuation. Using different arguments to reach a similar unbiased prices prediction, Hong and Stein (2003) assume perfectly rational arbitrageurs to remove any misvaluation.

Various proxies for the unobservable investor difference of opinion have been proposed for investigating the possible influence of diverse investor views on stock values; and, conflicting deductions have been drawn. Diether, Malloy, and Scherbina (2002) adopt analysts' earnings forecasts for measuring heterogeneity of investor beliefs and find that their divergence of opinion correlates to reversals in prices going forward. Goetzmann and Massa (2005) consider investor accounts trading data and find that difference of opinion associates positively to current stock-returns and 
negatively to one period ahead stock returns. Their results are indicative of the over-optimism on the part of investors rather than the additional risk factors being the primary mover for price changes. Hu. Meng and Potter (2008) similarly find investment managers' difference of opinion preceding lower returns, particularly for stocks which are hard to short. Overall, above-mentioned studies use dissimilar empirical metrics of investors' difference of opinion and document results supporting Miller's (1977) investor optimism hypothesis. However, other studies find evidence of the contrary.

Doukas et al. (2006) adopt a metric of divergence of opinion that is free from the noisy properties of analysts' estimates and find that stocks price changes are positively correlated to disagreement. Their findings are compatible with the asymmetric information explanation. Similarly, Garfinkel and Sokobin (2006) document a positive relation between disagreement, which is captured by abnormal trading volume, and post-earnings announcement drift in risk-adjusted returns. They interpret their result as that beliefs divergence represents a type of risk. Besides, Cragg and Malkiel (1982) find a positive relation between future returns and variance in analysts' forecasts. To further complicate matters, recent studies (Cao, Wang, \& Zhang, 2005; Johnson, 2004) suggest that the correlation between variance of analysts' earnings forecasts and future stock returns may be influenced by additional variables beside opinion differences or optimistic valuation. In summary, the various measures of opinion divergence, each having their advantages and drawbacks, lead to different results. Collectively, the weight of the empirical evidence until now suggests that more work is needed in the area.

We propose a novel metric of difference of opinion and study the impact of opinion divergence on asset returns. This new measure computes the magnitude of difference of opinion as the difference between the number of sell-side analysts upgrading and that downgrading a stock, normalized by total number of analysts changing their recommendations in the same period.

Our measure offers two advantages in capturing divergence of opinion. First, since our measure focuses on analysts' trading (buy or sell) recommendations, we capture divergence of opinion in an explicit and perhaps natural way. Divergence in sell-side analysts' trading recommendations directly reflects difference in their opinions on the valuation of a stock. Second, the literature has documented that the basis of our measure, i.e., analysts' recommendations, influences asset prices in a meaningful and material manner (Womack, 1996; Barber, Lehavy, McNichols, \& Trueman, 2001). This increases the discriminatory power of the empirical analyses in our study.

The primary results of our analyses are as follows. For our overall sample, there are positive and significant average abnormal returns contemporaneous to quarters of difference of opinion, followed by positive though insignificant abnormal returns in the subsequent months. Within the smallest tercile of firms a negative but insignificant average abnormal return is observed in the quarter of difference of opinion. Further, while abnormal stock price changes of the smallest capitalization stocks are lower than abnormal returns of the largest capitalization stocks, subsequent reversals in stock returns, as anticipated under the asymmetric information hypothesis, are not observed. Moreover, the results do not provide aid to the investor optimism hypothesis. For firms that have a low amount of institutional ownership, i.e., those facing more shorting constraints, both initial and subsequent abnormal stock returns are insignificant in the presence of analyst difference of opinion. Further, our results indicate that abnormal returns of stocks facing the most shorting constraints are not statistically different from those of stocks facing the least shorting constraints.

Our results appear to be inconsistent with the asymmetric information and investor optimism hypotheses, and instead somewhat support the unbiased prices hypothesis. Still, since the asymmetric information and investor optimism hypotheses predict offsetting impacts of investor difference of opinion on returns, it is possible that, in aggregate, the opposing impacts cancel out. This could especially be the case for stocks facing the largest magnitude of asymmetric information as well as the most severe shorting constraints. To further test the first two hypotheses versus the unbiased prices hypothesis, an additional round of analysis was conducted to isolate asymmetric information effects from the influence of shorting constraints by sorting our sample independently on the bases of institutional ownership and firm size. Although further findings on abnormal initial stock returns are compatible with the asymmetric information hypothesis and with the investor optimism hypothesis, there is no evidence of reversal in subsequent returns as predicted by the two hypotheses. The lack of significant reversals in stock returns is in accordance with the unbiased prices hypothesis. 


\section{DATA, DIFFERENCE OF OPINION MEASURE, AND METHODOLOGY}

\section{Data}

We link the CUSIP of the Institutional Brokers' Estimates System database with that of the CRSP monthly files for all U.S. firms the period of 1994-2010.

We compute our measure of difference of opinion among analysts, i.e., the analyst ratio $A(i, t)$, from their recommendations at the end of each quarter as follows:

$$
\mathrm{A}(\mathrm{i}, \mathrm{t})=\frac{U P(i, t)-D N(i, t)}{U P(i, t)+D N(i, t)}
$$

Here, UP(i,t) and DN(i,t) are, respectively, the number of analysts who upgraded and downgraded stock $i$ in quarter $t$. By using absolute difference of these quantities in the numerator, our measure emphasizes the degree of difference of opinion among analysts instead of the direction of difference of opinion. A low (high) value of $A(i, t)$ represents a high (low) level of difference of opinion. For example, if there are 5 upgrades and 5 downgrades on a stock in the same quarter, the zero value of A(i,t) reflects a low level of agreement (or a high level of difference of opinion) since the opinions of analysts are evenly split between the two opposite camps. In contrast, if there are 9 upgrades and 1 downgrade, then the $\mathrm{A}(\mathrm{i}, \mathrm{t})$ has a value of 0.8 signifying that most analysts are in agreement regarding their favorable view on the stock. A disagreement requires at least two analysts, so the measure is only computed for quarters in which two or more analysts change their recommendations. To determine whether there was an upgrade or a downgrade of a stock in a quarter, all outstanding recommendations within the 12-month period preceding the quarter were used (Jegadeesh, Kim, Krische, \& Lee, 2004). Since the rating scheme for analysts' recommendations is "Strong-Buy (1)", "Buy (2)", "Hold (3)", "Sell (4)", and "Strong-Sell (5)", any decrease (increase) in the rating, e.g., from 5 (4) to 4 (5), is classified as upgrade (downgrade). By concentrating on the direction of change in recommendation, our measure captures the degree of difference of opinion in a simple and explicit way.

In addition, we exclude analyst-stock-quarters where an analyst does not change his/her recommendation. Therefore, our sample consists of stock-quarters with a change in recommendation ${ }^{1}$, which has been documented as being more useful than the recommendation level (Jegadeesh et al., 2004). Other research has found that analysts tend to issue optimistic recommendations following a firm's IPO, so we exclude recommendations issued within the first year of the firm's IPO to mitigate the influence of biased recommendations. Our final sample consists of 49,135 stocksquarters, representing 6,121 unique stocks over 69 consecutive quarters. Within which there are 14,637 stock-quarters with upgrades and 34,498 stock-quarters with downgrades.

Besides, we compute several variables that capture characteristics of sample firms and stocks as follows. Volatility is measured with the standard deviation, of a stock's monthly raw returns over the most recent twelve months. Dispersion is defined as the standard deviation of analysts' earnings forecasts, which are extracted from the IBES Summary Historical files, scaled by the most recent stock price preceding the estimate day. Stock Turnover is defined as the average abnormal turnover computed from a stock's recent four quarters of exchange-adjusted turnover. Size is the natural logarithm of market capitalization, i.e., stock price multiplied by shares outstanding per the CRSP monthly files. Book-to-Market ratio is the ratio of book value of equity to market capitalization, where book value of equity is from COMPUSTAT annual files. Analyst Coverage is defined as the number of estimates used in computing average analysts' earnings forecasts. Past Return is defined as the recent six-month abnormal stock return, which is computed by compounding monthly abnormal stock returns determined using the four-factor model (Carhart, 1997).

\footnotetext{
. There were 260,266 analyst-stock-quarters in aggregate during the sample period. Of these, 150,894 analyst-stock-quarters had no change in recommendation, a result largely attributable to the infrequency with which analysts change their recommendations. Prior literature such as Womack (1996), and Jagadeesh et al. (2004) also focus on changes in recommendations as they are conveyed to investors immediately and nochanges are considered to be non-events with negligible impact on risk-adjusted stock returns.
} 


\section{Methodology}

We adopt Wermers (1999) and Fama and MacBeth (1973) in our methodology to study the impact of the magnitude of difference of opinion on stock returns. We examine the time series average of contemporaneous quarterly abnormal stock returns, and average monthly abnormal returns in the subsequent quarter of the stocks for which analysts display difference of opinions. We compute abnormal stock returns with Carhart's (1997) four-factor model as done in Hobbs, Lee and Singh. (2017).

The asymmetric information hypothesis argues that for stocks that sell-side analysts display less (greater) divergence of opinion in valuation, they are expected to experience larger (smaller) abnormal returns in the event quarter, and smaller (larger) abnormal returns in the following months. The investor optimism hypothesis, on the other hand, predicts that companies that are associated with less (greater) difference of opinion among analysts will experience lower (higher) abnormal initial returns in the contemporaneous quarter, followed by higher (lower) abnormal returns in subsequent months. Finally, the prediction of the unbiased prices hypothesis suggests that difference of opinion does not impact stock prices. Thus, stock valuation in the contemporaneous quarter as well as in subsequent months is not influenced by investors' difference of opinion, i.e., abnormal stock returns in contemporaneous and subsequent quarters would solely be due to new information being priced in.

\section{DESCRIPTIVE STATISTICS}

Table 1 compares characteristics of stocks that are associated with a great extent of difference of opinion among sellside analysts and stocks that face a small degree of difference of opinion. The magnitude of the difference of opinion is measured by the value of the analyst ratio, A $(\mathrm{i}, \mathrm{t})$, computed each quarter by sorting sample stocks into three groups. Stocks with their analyst ratios falling in the bottom (top) third of the sample are classified into the High (Low) Difference of opinion category, respectively. The comparison indicates that there is a greater magnitude of difference of opinion among analysts on stocks that have low turnover (0.156), which is statistically significantly different from that for stocks with low difference of opinion (0.260). This is interesting since many studies use abnormal turnover as the measure of difference of opinion among investors. Besides, companies that have lower book-to-market ratios and experienced more favorable past stock returns are associated with greater divergence of opinion among analysts than their peers. On the other hand, the High and Low Difference of opinion samples share similar statistics for volatility, firm size, analysts' coverage, and earnings forecast dispersion.

Table 1. Stock Characteristics and Degree of Difference of Opinion

\begin{tabular}{l|c|c}
\hline \multicolumn{1}{c}{ Stock Variable } & \multicolumn{2}{c}{ Difference of Opinion Among Analysts } \\
\cline { 2 - 3 } & High Difference & Low Difference \\
\hline Volatility & $12.440^{* * *}$ & $13.215^{* * *}$ \\
\hline Dispersion & $0.048^{*}$ & $0.044^{* * *}$ \\
\hline Stock Turnover & $0.156^{* * *}$ & $0.260^{* * *}$ \\
\hline Firm Size & $14.350^{* *}$ & $14.090^{* * *}$ \\
\hline Book-to-Market Ratio & $0.455^{* * *}$ & $0.536^{* * *}$ \\
\hline Analyst Coverage & $12.879^{* * *}$ & $11.987^{* * *}$ \\
\hline Past Return & $0.076^{* * *}$ & $0.012^{* * *}$ \\
\hline
\end{tabular}

$* * *, * * *$ represent $0.01,0.05$, and 0.10 levels of significance, respectively.

\section{RESULTS}

\section{Stock Returns for Firms Covered by Sell-side Analysts}

Table 2 reports average quarterly and monthly abnormal returns for stocks covered by analysts. "Qtr 0 " denotes the quarter in which the difference of opinion happened, and " $M+1$ ", " $M+2$ " and " $M+3$ " denote, respectively, the subsequent three months. When, for a particular stock, sell-side analysts disagree most, there is a positive though statistically insignificant average abnormal return in that quarter. Besides, the current quarter's abnormal returns of stocks in the High Difference of opinion category are statistically significantly higher than those of stocks in the Low 
Difference of opinion category. However, we fail to observe statistically significant reversals in abnormal returns during the subsequent months as predicted by both the investor optimism hypothesis and the asymmetric information hypothesis. Thus, the overall results do not seem to support these two hypotheses.

Table 2. Abnormal Stock Returns and Degree of Difference of Opinion

\begin{tabular}{l|c|c|c|c|c|c}
\hline \multicolumn{7}{|c}{ Degree of Difference of Opinion Among Sell Side Analysts and Abnormal Stock Returns } \\
\hline & Analyst Ratio & Qtr 0 & M+1 & M+2 & M+3 \\
\hline \multirow{2}{*}{ High Difference of opinion (HD) } & 0.029 & 0.338 & 0.415 & 0.162 & 0.247 \\
& $(<0.000)$ & $(0.181)$ & $(0.031)$ & $(0.325)$ & $(0.285)$ \\
\hline \multirow{2}{*}{ Medium Difference of opinion (MD) } & 0.423 & -0.271 & 0.279 & 0.474 & -0.061 \\
& $(<0.000)$ & $(0.244)$ & $(0.153)$ & $(0.038)$ & $(0.799)$ \\
\hline \multirow{2}{*}{ Low Difference of opinion (LD) } & 0.999 & -1.153 & 0.339 & 0.271 & -0.110 \\
HD-LD & $(<0.000)$ & $(<0.000)$ & $(0.108)$ & $(0.221)$ & $(0.591)$ \\
\hline \multirow{2}{*}{ HD } & -0.970 & 1.491 & 0.074 & 0.109 & 0.357 \\
\hline
\end{tabular}

The parentheses contain p-values for two-tailed t-tests.

In order to enhance the power of our empirical analysis and to gain further understanding of the impact of difference of opinion, in subsequent analysis we focus on stocks that are classified into the High Difference of opinion category.

\section{Difference of Opinion, Firm Size and Stock Returns}

To gain more insights into the asymmetric information hypothesis, we further classify stocks in the High Difference of opinion category into three groups based on firm size, which measures the extent of asymmetric information suggested by Frankel and $\mathrm{Li}(2004)$ and Wermers (1999). They argued that the additional risk connected with smaller stocks stems from a shortage of public information. We measure firm size with the natural logarithm of market capitalization at the beginning of the quarter of difference of opinion. Table 3 reports the time-series average of quarterly and monthly abnormal stock returns for the terciles. It is interesting to note that smallest firms have negative abnormal returns during the quarter of difference of opinion. This is compatible with the asymmetric information hypothesis that postulates stock prices of small firms are initially discounted due to added riskiness. According to the risk-discounting argument of the hypothesis, there should be higher subsequent abnormal returns to compensate for the higher risk; however, we observe no statistically significant reversion in abnormal returns in the subsequent period. Thus, we consider the findings to be unsupportive of the asymmetric information hypothesis.

Table 3. Difference of Opinion, Firm Size, and Abnormal Stock Returns

\begin{tabular}{l|c|c|c|c}
\hline \multicolumn{4}{c}{ Abnormal Stock Return under Analysts Disagreement, Sorted on Firm Size } \\
\hline & Qtr 0 & M+1 & M+2 & M+3 \\
\hline \multirow{2}{*}{ S1 (Smallest Firms) } & -0.406 & 0.574 & 0.152 & 0.312 \\
& $(0.206)$ & $(0.149)$ & $(0.603)$ & $(0.399)$ \\
\hline \multirow{2}{*}{ S2 (Middle Firms) } & 0.632 & 0.308 & -0.124 & 0.297 \\
& $(0.065)$ & $(0.273)$ & $(0.650)$ & $(0.195)$ \\
S3 (Largest Firms) & 0.798 & 0.377 & 0.441 & 0.127 \\
& $(0.003)$ & $(0.061)$ & $(0.020)$ & $(0.612)$ \\
S1-S3 & -1.204 & 0.197 & -0.289 & 0.185 \\
\end{tabular}

The parentheses contain p-values for two-tailed t-tests.

\section{Difference of Opinion, Shorting Constraints and Stock Returns}

To further test the investor optimism hypothesis, we sort stocks in the High Difference of opinion category by institutional ownership and present the results on abnormal returns in Table 4. Institutional ownership displays an inverse relationship with short-selling constraints as documented in Boehmer and Kelley (2009) and Zhao, Alexandridis, and Antoniou (2006). Hence, in line with the investor optimism hypothesis, we postulate that firms that 
have low institutional ownership yield "optimistic prices" in the current quarter along with negative abnormal returns in subsequent months. This inverse relation in abnormal returns should be most profound for stocks subject to most short-selling constraint (Miller, 1977; Boehmer, Danielsen, \& Sorescu, 2006). However, we instead find that contemporaneous abnormal stock returns in our low-institutional-ownership, most-shorting-constrained tercile (M1) are not significantly different from those in our high-ownership, least-constrained tercile (M3). That is, our findings do not support the investor optimism hypothesis.

Table 4. Difference of Opinion, Shorting Constraints, and Abnormal Stock Returns

\begin{tabular}{l|c|c|c|c}
\hline \multicolumn{4}{|c}{ Abnormal Stock Return under Analysts Disagreement, Sorted on Shorting Constraints } \\
\hline & Qtr 0 & M+1 & M+2 & M+3 \\
\hline \multirow{2}{*}{ M1 (Most Constrained) } & 0.196 & 0.575 & 0.150 & 0.423 \\
& $(0.504)$ & $(0.112)$ & $(0.519)$ & $(0.167)$ \\
\hline \multirow{2}{*}{ M2 (Moderately Constrained) } & 0.308 & 0.350 & 0.386 & 0.346 \\
& $(0.280)$ & $(0.117)$ & $(0.086)$ & $(0.215)$ \\
\hline \multirow{2}{*}{ M3 (Least Constrained) } & 0.479 & 0.292 & -0.061 & -0.031 \\
& $(0.152)$ & $(0.285)$ & $(0.801)$ & $(0.912)$ \\
\hline \multirow{2}{*}{ M1-M3 } & -0.283 & 0.282 & 0.211 & 0.454 \\
\end{tabular}

The parentheses contain p-values for two-tailed t-tests.

\section{Separating the Effects of Asymmetric Information and Shorting Constraints}

Institutional ownership is used throughout to proxy shorting constraints, and firm size is used to proxy information asymmetry. We have to be cautious in interpreting our results, however, because these two variables interact with each other. For example, as firm size increases, so does institutional ownership, suggesting that firms that likely have most asymmetric information also tend to face the most shorting constraints. Such an interaction imposes a challenging task to evaluate the relative merits between the asymmetric information and investor optimism hypotheses. Further, the offsetting predictions of these two hypotheses add to the challenge of differentiating them from the unbiased prices hypothesis.

Thus far, our only conclusion is that our data provide no clear evidence that either of the first two hypotheses dominates the other. The lack of a reversal in subsequent returns could support the unbiased prices hypothesis, or it could be because both the information optimism hypothesis and the asymmetric information hypothesis have merit but tend to cancel out one another. In order to avoid assigning a "false positive" to the unbiased prices hypothesis, a further analysis, which is detailed next, was performed to directly disentangle the first two hypotheses.

\section{Difference of Opinion, Shorting Constraints, and Size}

We further examine abnormal stock returns reported in Tables 3 and 4 with an independent sort of sample stocks. The High Difference of opinion sample is grouped into both institutional ownership terciles and market capitalization terciles. The abnormal returns of the resultant three-by-three grouping of sample stocks are presented in Table 5 . Panel C reports the abnormal returns for stocks that face limited constraints on shorting but that are associated with a great amount of asymmetric information. This combination is most favorable for examining the asymmetric information hypothesis, which predicts relatively low initial abnormal returns accompanied with high subsequent abnormal returns. Although we document a negative and highly significant initial abnormal return for the quarter during which analysts' display difference of opinion, there is no subsequent reversal in stock returns. In contrast, Panel A of Table 5, which features large, highly shorting-constrained firms, are favorable scenarios for testing the investor optimism hypothesis. For Panel A, though the statistically significant positive abnormal initial returns are consistent with the investor optimism hypothesis, the lack of significant subsequent reversal offers no further support for this hypothesis. Instead, Table 5 is consistent with the unbiased prices hypothesis. The general lack of reversals in stock returns during the subsequent months suggests that stock price changes occurring in the quarter of difference of opinion are not due to "optimistic prices" in the case of shorting-constrained firms or risk-discounting prices in the case of firms with high information asymmetry. 
Table 5. Difference of Opinion, Shorting Constraints, Size, and Abnormal Stock Returns

\begin{tabular}{|c|c|c|c|c|}
\hline \multicolumn{5}{|c|}{ Abnormal Stock Return under Analysts Disagreement, Sorted on Shorting Constraints } \\
\hline \multicolumn{5}{|c|}{ Panel A. (Most Constrained, M1) } \\
\hline & Qtr 0 & $\mathbf{M}+1$ & $\mathbf{M}+2$ & $\mathbf{M}+3$ \\
\hline S1 (Smallest Firms) & $\begin{array}{c}-2.738 \\
(<0.000)\end{array}$ & $\begin{array}{c}0.734 \\
(0.136)\end{array}$ & $\begin{array}{c}0.489 \\
(0.233)\end{array}$ & $\begin{array}{l}-0.325 \\
(0.265)\end{array}$ \\
\hline S2 (Middle Firms) & $\begin{array}{c}0.088 \\
(0.780)\end{array}$ & $\begin{array}{c}0.192 \\
(0.578)\end{array}$ & $\begin{array}{c}0.181 \\
(0.486)\end{array}$ & $\begin{array}{c}0.174 \\
(0.552)\end{array}$ \\
\hline S3 (Largest Firms) & $\begin{array}{c}0.483 \\
(0.084)\end{array}$ & $\begin{array}{c}0.466 \\
(0.033)\end{array}$ & $\begin{array}{l}-0.111 \\
(0.557)\end{array}$ & $\begin{array}{c}0.110 \\
(0.673)\end{array}$ \\
\hline \multicolumn{5}{|c|}{ Panel B. (Moderately Constrained, M2) } \\
\hline & Qtr 0 & M+1 & $\mathbf{M}+2$ & $\mathbf{M}+3$ \\
\hline S1 (Smallest Firms) & $\begin{array}{c}-1.745 \\
(<0.000)\end{array}$ & $\begin{array}{c}0.147 \\
(0.702)\end{array}$ & $\begin{array}{c}0.762 \\
(0.044)\end{array}$ & $\begin{array}{c}0.732 \\
(0.051)\end{array}$ \\
\hline S2 (Middle Firms) & $\begin{array}{c}0.177 \\
(0.597)\end{array}$ & $\begin{array}{c}0.398 \\
(0.157)\end{array}$ & $\begin{array}{c}0.440 \\
(0.116)\end{array}$ & $\begin{array}{l}-0.194 \\
(0.480)\end{array}$ \\
\hline S3 (Largest Firms) & $\begin{array}{c}0.393 \\
(0.035)\end{array}$ & $\begin{array}{c}0.457 \\
(0.026)\end{array}$ & $\begin{array}{c}0.419 \\
(0.009)\end{array}$ & $\begin{array}{c}0.073 \\
(0.754)\end{array}$ \\
\hline \multicolumn{5}{|c|}{ Panel C. (Least Constrained, M3) } \\
\hline & Qtr 0 & $\mathbf{M}+1$ & $\mathbf{M}+2$ & $\mathbf{M}+3$ \\
\hline S1 (Smallest Firms) & $\begin{array}{c}-1.971 \\
(<0.000)\end{array}$ & $\begin{array}{l}-0.003 \\
(0.993)\end{array}$ & $\begin{array}{c}0.216 \\
(0.584)\end{array}$ & $\begin{array}{c}0.372 \\
(0.293)\end{array}$ \\
\hline S2 (Middle Firms) & $\begin{array}{c}0.583 \\
(0.086)\end{array}$ & $\begin{array}{c}0.490 \\
(0.119)\end{array}$ & $\begin{array}{l}-0.057 \\
(0.809)\end{array}$ & $\begin{array}{c}0.035 \\
(0.894)\end{array}$ \\
\hline S3 (Largest Firms) & $\begin{array}{c}1.037 \\
(0.001) \\
\end{array}$ & $\begin{array}{l}-0.151 \\
(0.574) \\
\end{array}$ & $\begin{array}{c}0.076 \\
(0.766) \\
\end{array}$ & $\begin{array}{l}-0.206 \\
(0.505) \\
\end{array}$ \\
\hline
\end{tabular}

The parentheses contain p-values for two-tailed t-tests.

\section{CONCLUSION}

To study how investors' difference of opinions might affect stock returns, we present a new difference of opinion measure based on sell-side analysts' recommendations, using the imbalance of analysts' upgrades and downgrades as a proxy for belief heterogeneity. The new measure is used to examine the roles of the three hypotheses in explaining divergence of opinion on stock returns, namely, the asymmetric information hypothesis, the investor optimism hypothesis, and the unbiased prices hypothesis.

Our initial analysis offers little support for the asymmetric information and investor optimism hypotheses. As for the asymmetric information hypothesis, we sort the data by firm size, but fail to document the predicted reversal in stock returns though we do observe initial discounting in stock prices. As for the investor optimism hypothesis, we proxy shorting constraints by sorting by institutional, but do not find evidence of the predicted initial positive returns followed by reversals.

Though the initial findings seem to reject both the asymmetric information and investor optimism hypotheses and instead support the unbiased prices hypothesis, there are two reasons why we cannot immediately jump to such a conclusion. First, there are interaction among variables that measure asymmetric information and shorting constraints. Second, the asymmetric information and investor optimism hypotheses predict opposite impacts of difference of opinion on stock returns. Hence, it may indeed be the case that both of these hypotheses are valid, their offsetting impacts on stock returns may make the third unbiased prices hypothesis appear to be correct when in fact it is not. Our further findings indicate that companies that are most likely affected by either shorting constraints or asymmetric information, but not both, do not demonstrate the reversal posited by the respective hypothesis. Any price adjustment that occurs in the quarter of difference of opinion thus appears to be unbiased and is not resulted from risk-based discounting or over-optimism. Finally, we conclude that the overall evidence of this study supports the unbiased prices hypothesis, but not the asymmetric information hypothesis or the investor optimism hypothesis. 


\section{AUTHOR BIOGRAPHIES}

Jeffrey Hobbs is an Associate Professor of Finance, Walker College of Business, Appalachian State University, Boone, NC, 28608. He has published in Journal of Empirical Finance, Review of Quantitative Finance and Accounting, Review Financial Economics, and others. His primary research interests are in corporate finance including dividend policy, market efficiency, and agency theory. E-mail: hobbsjc@appstate.edu

David L. Kaufman is an Assistant Professor of Decision Sciences, College of Business, The University of MichiganDearborn. His previous industry experience includes product development at RiskMetrics Group. E-mail: davidlk@umich.edu

Hei-Wai Lee* is a Professor of Finance, College of Business, The University of Michigan-Dearborn, 19000 Hubbard Dr., Dearborn, MI, 48126. He has published in Financial Management, Financial Review, Journal of Business Research, Journal of Financial Research, and others. E-mail: heiwail@umich.edu (Contact author)

Vivek Singh is a Professor of Finance, College of Business, The University of Michigan-Dearborn. He has published in Financial Management, Journal of Banking and Finance, Journal of Empirical Finance, Journal of Financial Research, Journal of Business Research, and others. E-mail: vatsmala@umich.edu

\section{REFERENCES}

Barber, B., Lehavy, R., McNichols, M. \& Trueman, B. (2001). Can investors profit from the prophets? Security analysts recommendations and stock returns. Journal of Finance, 56(12), 531-563.

Boehmer, R., Danielsen, B. \& Sorescu, S. (2006) Short-sale constraints, differences of opinion and overvaluation. Journal of Financial and Quantitative Analysis, 41(2), 455-487.

Boehmer E. \& Kelley, E. (2009) Institutional investors and the informational efficiency of prices. Review of Financial Studies, 22(9), 3563-3594.

Cao, H., Wang, T. \& Zhang, H. (2005) Model uncertainty, limited market participation and asset prices. Review of Financial Studies, 18(4), 120-1251.

Carhart, M. (1997). On persistence in Mutual Fund performance. Journal of Finance, 52(1), 57-82.

Cragg. J. \& Malkiel, B. (1982). Expectations and the structure of share prices. Chicago, IL: Univ. of Chicago Press.

Diamond, D. \& Verrecchia, R. (1987). Constraints on short-selling and asset price adjustment to private information. Journal of Financial Economics, 18(2), 277-311.

Diether, K., Malloy, C. \& Scherbina, A. (2002). Differences of opinion and the cross section of stock returns. Journal of Finance, $57(5), 2113-2142$.

Doukas, J., Kim, C. \& Pantzalis, C. (2006). Divergence of opinion and equity returns. Journal of Financial and Quantitative Analysis, 41(3), 573-606.

Fama, E. \& MacBeth, J. (1973). Risk, return, and equilibrium: Empirical tests. Journal of Political Economy, 81(3), $607-636$.

Frankel, R. \& Li, X. (2004). Characteristics of a firm's information environment and the information asymmetry between insiders and outsiders. Journal of Accounting and Economics, 37(2), 229-259.

Garfinkel, J. \& Sokobin, J. (2006). Volume, opinion divergence, and returns: A study of post-earnings announcement drift. Journal of Accounting Research, 44(1), 85-112.

Goetzmann W. \& Massa, M. (2005). Dispersion of opinion and stock returns. Journal of Financial Markets, 8(3), 325-350.

Hobbs, J., Lee, H. \& Singh, S. (2017). New evidence on the effect of belief heterogeneity on stock returns. Review of Quantitative Finance and Accounting, 48(2), 289-309.

Hong, H. \& Stein, J. (2003). Differences of opinion, short-sales constraints, and market crashes. Review of Financial Studies, 16(2), 487-525.

Hu, G., Meng, J. \& Potter, M. (2008). Opinion divergence among professional investment managers. Journal of Business Finance \& Accounting, 35(5\&6), 679-703.

Jegadeesh, N., Kim, J., Krische, S. \& Lee, C. (2004). Analyzing the analysts: When do recommendations add value? Journal of Finance, 59(3), 1083-1124.

Johnson, T. (2004). Forecast dispersion and the cross section of expected returns. Journal of Finance, 59(5), $1957-1178$.

Merton, R. (1987). A simple model of capital market equilibrium with incomplete information. Journal of Finance, 42(3), 483510.

Miller, M. (1977). Risk, uncertainty and divergence of opinion. Journal of Finance, 32(4), 1151-1168.

Varian, H. (1985). Divergence of opinion in complete markets: A note. Journal of Finance, 40(1), 309-317.

Wermers, R. (1999). Mutual Fund trading and the impact on stock prices. Journal of Finance, 54(2), 581-622. 
Womack, K. (1996). Do brokerage analysts' recommendations have investment value? Journal of Finance, 51(1), $137-167$.

Zhao, H., Alexandridis, G. \& Antoniou, A. (2006). Valuation effects of short sale constraints: The case of corporate takeovers. European Financial Management, 12(5), 747-762. 


\section{NOTES}

